\title{
Low consumption of fruits and vegetables among adults in Uganda: findings from a countrywide cross-sectional survey
}

\author{
Steven Ndugwa Kabwama ${ }^{1 *} \mathbb{D}$, Silver K. Bahendeka ${ }^{2}$, Ronald Wesonga ${ }^{3}$, Gerald Mutungi ${ }^{4}$ and David Guwatudde ${ }^{5}$
}

\begin{abstract}
Introduction: Adequate consumption of fruits and vegetables has protective benefits against development of coronary heart disease, hypertension and chronic obstructive pulmonary disease. However, approximately 2.7 million deaths annually can be attributed to inadequate fruit and vegetable consumption. We analyzed data from a countrywide survey in Uganda, to estimate the prevalence of adequate fruit and/ or vegetable consumption, and identify associated factors.

Methods: Data were collected using the World Health Organization STEPwise approach to surveillance, a standard approach to surveillance of risk factors for Non Communicable Diseases. Fruit and vegetable consumption was assessed by asking participants the number of days in a typical week they eat fruits or vegetables and the number of servings eaten in one of those days. Adequate fruit and/ or vegetable consumption was defined as consuming 5 or more servings of fruits and/ or vegetables per day in a typical week. We used modified Poisson regression analysis to estimate prevalence risk ratios (PRRs) and identify factors associated with eating 5 or more servings of fruits and/ or vegetables per day, per week.
\end{abstract}

Results: Of 3962 participants, 484 (12.2\%) consumed 5 or more servings of fruits and/ or vegetables per day in a typical week. Participants who were married or cohabiting were more likely to consume at least 5 servings of fruits and/ or vegetables per day in a typical week compared with those who had never been married PRR $=1.51[95 \% \mathrm{Cl}$ 1.07-2.14]. Compared with participants from Western region, those from Central region were more likely to consume 5 or more servings of fruits and/ or vegetables per day in a typical week, PRR $=3.54[95 \% \mathrm{Cl} 2.46-5.10]$ as were those from Northern, PRR $=2.90[95 \% \mathrm{Cl} 2.00-4.23]$ and Eastern regions PRR $=1.60[95 \% \mathrm{Cl} 1.04-2.47]$.

Conclusions: Fruit and vegetable consumption in Uganda is low and does not differ significantly across social and demographic characteristics, except marital status and geographical region of residence. There is a need to develop and strengthen policies that promote adequate consumption of fruits and vegetables in the Ugandan population.

Keywords: Fruit and vegetable, Diet, Nutrition, WHO STEPs methodology, Sub-Saharan Africa, Uganda

\section{Introduction}

According to the World Health Organization (WHO), approximately 2.7 million deaths annually can be attributed to inadequate consumption of fruits and vegetables [1]. This figure includes $11 \%$ of strokes and $31 \%$ of ischemic heart diseases worldwide. A systematic review and meta-analysis of prospective studies investigating the association between fruit and vegetable consumption

\footnotetext{
* Correspondence: skabwama@musph.ac.ug

${ }^{1}$ Makerere University School of Public Health, Kampala, Uganda

Full list of author information is available at the end of the article
}

and all-cause mortality established that the average reduction of mortality risk was $5 \%$ for each additional serving of fruits and vegetables per day [2]. More specifically, consumption of fruits and vegetables has been shown to have protective benefits against development of coronary heart disease, hypertension and chronic obstructive pulmonary disease [3]. Although the benefits of consuming fruits and vegetables are well documented, a World Health Survey that compared fruit and vegetable consumption across 52 low and middle income countries found that only about $30 \%$ of men and women

(c) The Author(s). 2019 Open Access This article is distributed under the terms of the Creative Commons Attribution 4.0 International License (http://creativecommons.org/licenses/by/4.0/), which permits unrestricted use, distribution, and 
consumed more than the recommended minimum of 5 servings of fruits and/ or vegetables every day [4]. Fruits and vegetables are an important source of vitamins, vital minerals and dietary fiber which in itself has been associated with lower incidence of obesity [5]. In spite of the importance of consuming fruits and vegetables to human health, there is scanty information regarding the levels and adequacy of consumption of fruits and vegetables in Uganda.

In 2014, a countrywide survey was conducted to provide baseline estimates of the 4 major risk factors for non-communicable diseases (NCDs) including physical activity, alcohol use, tobacco use, as well as fruits and vegetables consumption among adults in Uganda. We analyzed data from this survey to provide national level estimates of the consumption of fruits and vegetables among adults in Uganda. Findings from the analysis can be used to inform development of comprehensive nutrition interventions and the implementation of the Uganda National Food and Nutrition Policy [6].

\section{Methods}

\section{Study design}

The Uganda National NCD Risk Factor Survey was conducted using a cross sectional study design, and data were collected between March and July 2014. The survey used the World Health Organization's (WHO) STEPwise approach to surveillance, standardized method of collecting data on risk factors for NCDs [7]. Details about the conduct of the survey, including the sample size calculation and sampling procedures have all been described in previous publications [8-10]. We give a brief description of the sampling and methods used.

\section{Sampling}

The survey utilized a three stage sampling design to obtain a sample that is representative of the national population. In the first stage, 350/ 78,950 enumeration areas were randomly selected from the Uganda Bureau of Statistics sampling frame of enumeration areas that was used during the 2014 population and housing census using probability proportionate to size sampling and stratified by the four geographical regions. The enumeration areas were selected with separate estimates for urban and rural areas. Urban areas were those classified as such by government designation or with a population density higher than 1000 people per square $\mathrm{km}$. In the second stage, all households in each of the 350 enumeration areas were listed and 14 households were randomly selected. In the final stage, a member of the household aged 18-69 years was randomly selected to participate in the survey.

\section{Measurements}

Data were collected in 3 steps in accordance with the standard WHO STEPwise approach to Surveillance questionnaire [7] as follows: In STEP 1, data were collected on socio-demographic and behavioral characteristics including alcohol and tobacco use, fruit and vegetable consumption and level of physical activity (PA). Fruits and vegetables consumption was assessed by asking participants the number of days in a typical week when they eat fruits or vegetables; and when they do, the number of servings of fruit or vegetables eaten in one of those days. A show card was used to show participants pictures of examples of commonly available fruits and vegetables in Uganda, with each picture representing the size of one serving. Participants were also asked whether within the past 3 years they had received lifestyle advice from a medical worker or other health worker to eat at least 5 servings of fruits and/ or vegetables each day.

In STEP 2, physical measurements including body height, body weight and blood pressure were made. Finally in STEP 3, a blood sample was collected to assess fasting plasma glucose using a CardioChek ${ }^{\circ} \mathrm{PA}$ meter $[8,10]$.

Data collection was conducted over 2 days whereby the interview (STEP 1) and physical measurements (STEP 2) were done on the first day while the biochemical measurements (STEP 3) were conducted the next day among participants reporting compliance with an overnight 8-h fast, no exercise or smoking.

\section{Statistical analysis}

Due to their low caloric content and high fiber and nutrient density, the recommended level of consumption of fruits and/ or vegetables is a minimum of 5 servings per day $[4,11,12]$. Based on this recommendation, we created a binary variable of those who reported consuming less than 5 servings of fruits and/ or vegetables (including those who did not eat any per week); and those who reported consuming at least 5 servings. We then used weighted modified Poisson regression modeling to identify characteristics of the participants associated with consuming at least 5 servings of fruits and/ or vegetables, with the participant sampling selection fractions as the weights. Weighted modified Poisson regression was preferred over logistic regression to avoid under estimation of the standard errors of the estimated risk ratios [13-15]. Thus we estimated both the crude and adjusted prevalence risk ratios (PRRs) and their corresponding 95\% confidence intervals (CIs) as the measure of association between the binary outcome of consuming at least 5 servings of fruits and vegetables per day in a typical week, or not. Model fitting was conducted first including in the model, all social, demographic, and physical 
characteristic variables of the participants measured. Then backward stepwise elimination was used to remove variables not significantly associated with the outcome. Variables were removed one at a time, starting with the least significantly associated with the outcome. The cut-off for statistical significance was a $p$-value of $<0.05$. Therefore, variables with a $\mathrm{p}$-value $\geq 0.05$ were removed from the model. The independent variables investigated during modelling included: sex, age, level of education, marital status, geographical region of residence, employment status, urban or rural residence, Body Mass Index (BMI), blood pressure and Fasting Plasma Glucose (FPG) level, having received lifestyle advice to consume at least 5 servings of fruits and vegetables per day. When building a multiple regression model, including variables that are highly correlated affects the integrity of the model leading to wrong estimates of the standard errors [16]. We thus investigated multicollinearity in the regression model using the variance inflation factor where by a mean variance inflation factor less than 10 showed that there was no multicollinearity. The pairs of variables investigated include level of education and urban/ rural residence, employment status and level of education and urban/ rural residence and employment status. All statistical analyses were performed using STATA version 12 (StataCorp, College Station, Texas, USA).

\section{Results}

\section{Characteristics of participants}

Of the targeted study sample of 4100,3987 consented to participate, yielding a response rate of $97 \%$. Among these, 3962 had data on fruit and vegetable consumption and are therefore included in this analysis, of which 2371 (59.8\%) were females, 2886 (72.8\%) were rural residents, 2634 (66.4\%) were either married or cohabiting, and 2585 (65.2\%) were in employment (Table 1).

\section{Levels of fruit and vegetable consumption}

Among the participants in the survey, 484 (12.2\%) reported consuming 5 or more servings of fruits and/ or vegetables per day in a typical week. Among participants who had never been married, $560(89.9 \%)$ consumed $<5$ servings of fruits and/ or vegetables in a day in a typical week while $63(10.1 \%)$ consumed $\geq 5$ servings in a day in a typical week. Among those who were married on the other hand, $2298(87.2 \%)$ consumed $<5$ servings of fruits and/ or vegetables a day in a typical week and 336 (12.8\%) consumed $\geq 5$ servings of fruits and/ or vegetables a day in a typical week. The distribution of consumption of the different servings of fruits and vegetables is summarized in Table 2.
Table 1 Characteristics of participants in the survey

\begin{tabular}{|c|c|c|}
\hline Characteristic & $\begin{array}{l}-\mathrm{n}- \\
(n=3962)\end{array}$ & $\begin{array}{l}\text { Summary measure } \\
(\%)\end{array}$ \\
\hline \multicolumn{3}{|l|}{ Sex } \\
\hline Male & 1591 & 40.2 \\
\hline Female & 2371 & 59.8 \\
\hline \multicolumn{3}{|l|}{ Age group, years } \\
\hline $18-29$ & 1610 & 40.6 \\
\hline $30-49$ & 1666 & 42.1 \\
\hline $50-69$ & 686 & 17.3 \\
\hline \multicolumn{3}{|l|}{ Residence } \\
\hline Urban & 1076 & 27.2 \\
\hline Rural & 2886 & 72.8 \\
\hline \multicolumn{3}{|l|}{ Region } \\
\hline Western & 940 & 23.7 \\
\hline Central & 962 & 24.3 \\
\hline Northern & 778 & 19.6 \\
\hline Eastern & 1282 & 32.4 \\
\hline \multicolumn{3}{|l|}{ Ethnicity } \\
\hline Baganda & 768 & 19.4 \\
\hline Banyankore/ Bakiga & 698 & 17.6 \\
\hline Basoga & 315 & 7.9 \\
\hline Banyoro/ Batooro & 257 & 6.5 \\
\hline Lugbara/ Madi & 249 & 6.3 \\
\hline Other & 1675 & 42.3 \\
\hline \multicolumn{3}{|l|}{ Marital status } \\
\hline Never married & 623 & 15.7 \\
\hline Married/ Cohabiting & 2634 & 66.4 \\
\hline Separated/ Divorced/ Widowed & 702 & 17.8 \\
\hline \multicolumn{3}{|l|}{ Completed level of education } \\
\hline No formal school & 649 & 15.7 \\
\hline Primary school & 1614 & 40.7 \\
\hline Secondary school & 1310 & 33.1 \\
\hline University or higher & 374 & 9.4 \\
\hline \multicolumn{3}{|l|}{ Employment status } \\
\hline Employed & 2585 & 65.2 \\
\hline Unemployed & 1376 & 34.7 \\
\hline \multicolumn{3}{|l|}{$B M l^{\mathrm{a}}\left(\mathrm{kg} / \mathrm{m}^{2}\right)$} \\
\hline Underweight, < 18.5 & 328 & 8.3 \\
\hline Normal weight, 18.5-24.9 & 2518 & 63.6 \\
\hline Overweight or Obese, $\geq 25$ & 1116 & 28.2 \\
\hline
\end{tabular}

aody Mass Index

Factors associated with fruits and/ or vegetable consumption

The three pairs of variables investigated for multicollinearity yielded mean variance inflation factors less than 
Table 2 Distribution of number of servings of fruits and/ or vegetables eaten per day in a typical week, by characteristics of participants

\begin{tabular}{|c|c|c|c|c|}
\hline \multirow[t]{2}{*}{ Variable } & \multirow[t]{2}{*}{$-n-$} & \multicolumn{2}{|c|}{ Servings of fruits and/ or vegetables consumed } & \multirow[t]{2}{*}{$p$-value } \\
\hline & & $\begin{array}{l}<5 \text { servings } \\
n(\%)\end{array}$ & $\begin{array}{l}\geq 5 \text { servings } \\
n(\%)\end{array}$ & \\
\hline All participants & 3962 & $3478(87.8)$ & $484(12.2)$ & $\mathrm{n} / \mathrm{a}$ \\
\hline \multicolumn{5}{|l|}{ Sex } \\
\hline Males & 1591 & $1384(87.0)$ & $207(13.0)$ & \multirow[t]{2}{*}{0.21} \\
\hline Females & 2371 & $2094(88.3)$ & $277(11.7)$ & \\
\hline \multicolumn{5}{|l|}{ Age } \\
\hline $18-29$ & 1610 & $1432(88.9)$ & $178(11.1)$ & \multirow[t]{3}{*}{0.17} \\
\hline $30-49$ & 1666 & $1452(87.2)$ & $214(12.8)$ & \\
\hline $50-69$ & 686 & $594(86.6)$ & $92(13.4)$ & \\
\hline \multicolumn{5}{|l|}{ Marital status } \\
\hline Never married & 623 & $560(89.9)$ & $63(10.1)$ & \multirow[t]{3}{*}{0.19} \\
\hline Married/Cohabiting & 2634 & $2298(87.2)$ & $336(12.8)$ & \\
\hline Separated/Divorced/ Widowed & 702 & $617(87.9)$ & $85(12.1)$ & \\
\hline \multicolumn{5}{|l|}{ Level of education } \\
\hline No formal schooling & 649 & $566(87.2)$ & $83(12.8)$ & \multirow[t]{4}{*}{0.70} \\
\hline Primary & 1614 & $1408(87.2)$ & $206(12.8)$ & \\
\hline Secondary & 1310 & $1158(88.4)$ & $152(11.6)$ & \\
\hline University or higher & 374 & $332(88.8)$ & $42(11.2)$ & \\
\hline \multicolumn{5}{|l|}{ Region of residence } \\
\hline Western & 940 & $890(94.7)$ & $50(5.3)$ & \multirow[t]{4}{*}{$<0.05$} \\
\hline Central & 962 & $766(79.6)$ & $196(20.4)$ & \\
\hline Northern & 778 & $636(81.7)$ & $142(18.3)$ & \\
\hline Eastern & 1282 & $1186(92.5)$ & $96(7.5)$ & \\
\hline \multicolumn{5}{|l|}{ Rural-urban residence } \\
\hline Urban & 1076 & $976(90.7)$ & $100(9.3)$ & \multirow[t]{2}{*}{$<0.05$} \\
\hline Rural & 2886 & $2502(86.2)$ & $384(13.8)$ & \\
\hline \multicolumn{5}{|l|}{ Employment } \\
\hline Employed & 2585 & $2283(87.8)$ & $302(12.2)$ & \multirow[t]{2}{*}{0.16} \\
\hline Unemployed & 1376 & $1194(86.7)$ & $182(13.3)$ & \\
\hline \multicolumn{5}{|l|}{ BMI $\left(\mathrm{kg} / \mathrm{m}^{2}\right)$} \\
\hline 18.5-24.9 Normal weight & 2518 & $2201(87.4)$ & $317(12.6)$ & \multirow[t]{3}{*}{0.40} \\
\hline < 18.5 Underweight & 328 & $285(87.0)$ & $43(13.0)$ & \\
\hline$\geq 25$ Overweight or Obese & 1116 & $992(88.9)$ & $124(11.1)$ & \\
\hline
\end{tabular}

10 meaning that there was no multicollinearity in the regression model.

Only marital status and geographical region of residence were the factors found to be statistically significantly associated with eating 5 or more servings of fruits and/ or vegetables per day in a typical week. Participants who were married or cohabiting were more likely to consume 5 or more servings of fruits and/ or vegetables per day in a typical week compared with those who had never been married, PRR $=1.51$ [95\% CI 1.07-2.14]. Further, compared with participants resident in the Western region of the country, those resident in the Central region were more likely to consume 5 or more servings of fruits and/ or vegetables per day in a typical week, $\mathrm{PRR}=3.54[95 \% \mathrm{CI}$ 2.46-5.10]; as were residents in the Northern, $\mathrm{PRR}=2.90$ [95\% CI 2.00-4.23], and Eastern regions of the country, $\mathrm{PRR}=1.60$ [95\% CI 1.04-2.47]. The rest of the results from association analysis are presented in Table 3. 
Table 3 Crude and Adjusted Prevalence Risk Ratios (PRR) of consuming $\geq 5$ servings of fruits and/ or vegetables per day in a typical week among participants in the survey

\begin{tabular}{|c|c|c|c|c|}
\hline Variable & $-n-$ & $\begin{array}{l}\geq 5 \text { servings } \\
n(\%)\end{array}$ & Crude PRR [95\% Cl] & Adjusted PRR $[95 \% \mathrm{Cl}]^{\mathrm{a}}$ \\
\hline \multicolumn{5}{|l|}{ Sex } \\
\hline Males & 1591 & $207(13.0)$ & 1.0 & 1.0 \\
\hline Females & 2371 & $277(11.7)$ & $0.82[0.64-1.05]$ & $0.82[0.64-1.04]$ \\
\hline \multicolumn{5}{|l|}{ Age } \\
\hline $18-29$ & 1610 & $178(11.1)$ & 1.0 & 1.0 \\
\hline $30-49$ & 1666 & $214(12.8)$ & $1.11[0.84-1.47]$ & $1.15[0.87-1.52]$ \\
\hline $50-69$ & 686 & $92(13.4)$ & $1.03[0.74-1.45]$ & $1.20[0.86-1.67]$ \\
\hline \multicolumn{5}{|l|}{ Marital status } \\
\hline Never married & 623 & $63(10.1)$ & 1.0 & 1.0 \\
\hline Married/Cohabiting & 2634 & $336(12.8)$ & $1.52[1.04-2.21]$ & $1.51[1.07-2.14]$ \\
\hline Separated/Divorced/ Widowed & 702 & $85(12.1)$ & $1.38[0.88-2.17]$ & $1.46[0.98-2.17]$ \\
\hline \multicolumn{5}{|l|}{ Level of education } \\
\hline No formal schooling & 649 & $83(12.8)$ & 1.0 & 1.0 \\
\hline Primary & 1614 & $206(12.8)$ & $0.86[0.63-1.16]$ & $0.91[0.67-1.22]$ \\
\hline Secondary & 1310 & $152(11.6)$ & $0.98[0.68-1.41]$ & $1.06[0.76-1.47]$ \\
\hline University or higher & 374 & $42(11.2)$ & $0.76[0.47-1.22]$ & $0.84[0.54-1.31]$ \\
\hline \multicolumn{5}{|l|}{ Region of residence } \\
\hline Western & 940 & $50(5.3)$ & 1.0 & 1.0 \\
\hline Central & 962 & $196(20.4)$ & 3.54 [2.40-5.22] & 3.54 [2.46-5.10] \\
\hline Northern & 778 & $142(18.3)$ & $2.83[1.88-4.27]$ & $2.90[2.00-4.23]$ \\
\hline Eastern & 1282 & $96(7.5)$ & $1.45[0.92-2.27]$ & $1.60[1.04-2.47]$ \\
\hline \multicolumn{5}{|l|}{ Rural-urban residence } \\
\hline Urban & 1076 & $100(9.3)$ & 1.0 & 1.0 \\
\hline Rural & 2886 & $384(13.8)$ & $1.00[0.74-1.35]$ & 0.99 [0.75-1.30] \\
\hline \multicolumn{5}{|l|}{ Employment } \\
\hline Employed & 2585 & $302(12.2)$ & 1.0 & 1.0 \\
\hline Unemployed & 1376 & $182(13.3)$ & $0.99[0.74-1.32]$ & $0.92[0.70-1.22]$ \\
\hline \multicolumn{5}{|c|}{ Received lifestyle advice on fruit and/ or vegetable consumption } \\
\hline No & 2916 & $359(12.3)$ & 1.0 & 1.0 \\
\hline Yes & 890 & $123(13.8)$ & $1.21[0.92-1.60]$ & $1.18[0.90-1.54]$ \\
\hline \multicolumn{5}{|l|}{$\mathrm{BMI}\left(\mathrm{kg} / \mathrm{m}^{2}\right)$} \\
\hline 18.5-24.9 Normal weight & 2518 & $317(12.6)$ & 1.0 & 1.0 \\
\hline$<18.5$ Underweight & 328 & $43(13.0)$ & $0.88[0.61-1.26]$ & $0.86[0.60-1.22]$ \\
\hline$\geq 25$ Overweight or Obese & 1116 & $124(11.1)$ & $1.03[0.78-1.37]$ & $0.98[0.75-1.28]$ \\
\hline
\end{tabular}

${ }^{a}$ Adjusted for marital status and geographical region of residence

\section{Discussion}

The analysis of data from this countrywide survey has revealed that the majority of adults in Uganda do not meet the recommended minimum requirements for fruit and vegetable consumption, with just over 1 in 10 adults meeting the recommended minimum of 5 or more servings of fruits and/ or vegetables per day in a typical week. Other countries in the region such as the Democratic Republic of Congo have also reported a closely low prevalence at $12.1 \%$
[17], whereas others such as the Republic of Tanzania, Zambia and Mozambique have reported much lower prevalence at 2.8, 3 and $5 \%$ respectively [18-20]. The low prevalence of adequate consumption of fruits and/ or vegetables in Sub-Saharan Africa has been attributed to variations in the availability of the fruits and vegetables in the region [21]. Indeed, the availability of fruits and vegetables per person per year is $105.5 \mathrm{~kg}$ in the African region and $64.2 \mathrm{~kg}$ per person per year in Uganda, way below the 146 
kg per person per year recommended by the World Health Organization and the Food and Agriculture Organization [1]. The low consumption of fruits and vegetables has also been explained by cultural dietary patterns and an increasing urbanization rate in Sub-Saharan Africa [21]. In Uganda, the low availability of fruits and vegetables could be attributed to the limited knowledge about their nutritional value and the emphasis of cultivating commercial agricultural products such as roots/ tubers and cereals from which farmers earn income [22]. A health in all policies approach [23] should be adopted in the design and formulation of policies that promote income generation and poverty reduction so that health and nutrition are promoted in parallel with interventions that spur economic development.

The factors found significantly associated with adequate consumption of fruits and/ or vegetables were marital status and geographical region of residence. Previously published literature has shown that age [24], gender [24, 25], level of education [24-26] and knowledge about fruits and vegetables [27] are significant predictors of adequate fruit and vegetable consumption. Our analysis did not find these to be significantly associated with fruit and vegetable consumption. This is likely to be because the level of fruit and vegetable consumption is about the same in the Ugandan context, with the population differing by only a few demographic variables. Participants who were married were more likely to consume 5 or more servings of fruits and/ or vegetables in a typical week. The association between marital status and fruits and vegetable consumption where married people consume more fruits and vegetables compared with their unmarried counterparts is no surprise finding and has been documented in other studies [28-30]. Marriage and companionship involve social interactions which set the stage for higher food consumption as a result of a regular pattern of meals [30] that include fruits and vegetables. This observation could be explained by the theoretical model of social integration and social control where by marriage is associated with efforts to control health behavior among spouses [30, 31]. This control of health behavior could involve a spouse preparing meals rich in fruits and vegetables or ensuring the availability of the fruits and vegetables in the home.

Participants from some regions of residence in the county were statistically significantly more likely to consume the recommended 5 or more servings of fruits and/ or vegetables per day in a typical week compared with those from the Western region. This finding is corroborated by results from a food consumption survey that established that there are substantial variations across the geographical regions in Uganda regarding food and micronutrient consumption [32]. The diets in the various regions are based on locally available and commonly cultivated staples that are presumed to be nutrient dense [33]. Each geographical region has certain ethnicities part of whose cultural identities are the traditional staples consumed in that region [34]. Thus our findings regarding these regional differences are not surprising. Previous reports have also documented poor nutrition among people from the western region of the country [35-37]. A survey carried out in Western Uganda found that about 7 in 10 adults in the region have only 2 meals a day [38] such that food choices and dietary patterns are based on their energy and caloric content and not the variety in nutrient composition. Indeed, the Uganda National Household Survey 2016/2017 showed that in the week that preceded the survey, the Western region reported the highest prevalence of low dietary diversity where $43 \%$ of households reported to have consumed fewer than 5 of the 7 food groups (cereals/ tubers, pulses/ nuts, fruits, vegetables, milk, meat/ fish/ eggs and oil) [39]. Policies and interventions to improve nutritional status and enhance fruit and vegetable consumption in the country should take into account the cultural diversity across the geographical regions and its influence on food choices.

\section{Limitations}

There are limitations to the interpretation of the findings from the analysis. The dependent variable where participants reported the number of days in a typical week when they eat fruits or vegetables and the number of servings of fruit or vegetables consumed in one of those days was based on self-reports which introduces information bias. The use of a nutrition card to aid participants in estimating the size of a serving does reduce but cannot totally eliminate this bias. This challenge of using self-reports in diet and nutritional epidemiology to assess food consumption in terms of quantity and frequency is not new and has been documented and findings critiqued in previous literature [40]. However, there is also a substantial body of evidence to show that there are no significant differences between estimates of nutrient intake using weighed records and recall questionnaires [41] as is the case with the recall of the number of servings of fruits and vegetables that was used in the current paper. Furthermore, even though the validity of the individual survey question on fruit and vegetable consumption remains to be validated in the study population, the validity of other forms of recall measures of fruit consumption is supported in the European population by the Bingham study [41]. Vegetable intake however remains uncertain. Thus the presence of this bias could have affected the validity of the results. We also acknowledge the possibility of a selection bias that could have been introduced because the data collection was 
carried out during the day at times when men are more likely to be away from home which could explain the disproportionately higher number of female participants compared with males. Indeed, the prevalence of consumption of adequate servings of fruits and vegetables was higher among males (13.0\%) compared with females (11.7\%) because of the larger denominator which could have biased the results away from the null. Also, in the assessment of fruit and/ or vegetable intake, participants were asked the number of days in a typical week when they eat fruits or vegetables; and when they do, the number of servings of fruit or vegetables eaten in one of those days. The word 'typical' is vague and its interpretation was left to the interviewee which could have introduced bias.

\section{Conclusions}

The results from this country-wide survey have shown that there is low fruit and vegetable consumption in Uganda. There is a need to better understand the level of people's understanding of fruits and vegetables and whether nutritional education may be an appropriate focus for the improvement of dietary behaviors among adults in Uganda. The design and development of policies to promote agricultural related socio-economic development should take into account the influence that these policies have on food options and choices. Fruit and vegetable consumption was only associated with geographical region of residence and marital status which may be a reflection of cultures in which food choices are part of cultural and ethnic identities. Policies and interventions to improve nutritional status and enhance fruit and vegetable consumption in the country should take into account the cultural diversity across the geographical regions and its influence on food choices.

\section{Abbreviations}

BMI: Body Mass Index; STEPS: Stepwise Approach to Surveillance; WHO: World Health Organization

\section{Acknowledgements}

The authors are grateful to the research participants who volunteered to participate in the NCD risk factor prevalence survey; and for the technical and administrative support provided by Uganda's Ministry of Health, and that from the Uganda Bureau of Statistics. The authors also acknowledge the technical support provided by Melanie Cowan and Lubna Ishaq Bhatti of the Surveillance and Population-based Prevention Unit, Department of Prevention of Non-communicable Diseases, Non-communicable Diseases and Mental Health Cluster, World Health Organization, Geneva, Switzerland.

\section{Funding}

The conduct of the survey was supported by funding from the Uganda government, the World Health Organization, the World Diabetes Foundation, and the United Nations Development Program. The funders had no role in study design, data collection and analysis, decision to publish, or preparation of the manuscript.

\section{Availability of data and materials}

The dataset supporting the conclusion of this article can be accessed by writing an email to the first author.

\section{Authors' contributions}

GM, SKB, RW and DG conceived and designed the study. SKB, RW, DG and GM implemented the study. SNK and DG analyzed the data. DG and SNK had primary responsibility for final content. All authors participated in writing, read and approved the final manuscript.

\section{Ethics approval and consent to participate}

Written informed consent was obtained from eligible selected participants before conducting any study procedures. The conduct of the survey was approved by the Institutional Review Committee of Nsambya Hospital, Kampala, Uganda, and registered by the Uganda National Council for Science and Technology (UNCST).

\section{Consent for publication}

N/A.

\section{Competing interests}

The authors declare that they have no competing interests.

\section{Publisher's Note}

Springer Nature remains neutral with regard to jurisdictional claims in published maps and institutional affiliations.

\section{Author details}

${ }^{1}$ Makerere University School of Public Health, Kampala, Uganda. ${ }^{2}$ St. Francis Hospital, Nsambya, Kampala, Uganda. ${ }^{3}$ School of Statistics and Planning, Makerere University College of Business and Management Sciences, Kampala, Uganda. ${ }^{4}$ Control of Non-Communicable Diseases Desk, Ministry of Health, Kampala, Uganda. ${ }^{5}$ Department of Epidemiology \& Biostatistics, School of Public Health, Makerere University College of Health Sciences, Kampala, Uganda.

Received: 22 October 2018 Accepted: 16 January 2019

Published online: 07 February 2019

\section{References}

1. Ruel MT, Minot N, Smith L. Patterns and determinants of fruit and vegetable consumption in sub-Saharan Africa: a multicountry comparison. Geneva: WHO; 2005

2. Wang $X$, Ouyang $Y$, Liu J, Zhu M, Zhao G, Bao W, et al. Fruit and vegetable consumption and mortality from all causes, cardiovascular disease, and cancer: systematic review and dose-response meta-analysis of prospective cohort studies. BMJ. 2014;349:94490.

3. Van Duyn MAS, Pivonka E. Overview of the health benefits of fruit and vegetable consumption for the dietetics professional: selected literature. J Am Diet Assoc. 2000;100(12):1511-21.

4. Hall JN, Moore S, Harper SB, Lynch JW. Global variability in fruit and vegetable consumption. Am J Prev Med. 2009;36(5):402-9 e5.

5. Slavin JL, Lloyd B. Health benefits of fruits and vegetables. Adv Nutr. 2012; 3(4):506-16.

6. Uganda Ministry of Agriculture Animal Industries and Fisheries, Uganda Ministry of Health. The Uganda Food and Nutrition Policy, 2003. 2003. Accessible from https://extranet.who.int/nutrition/gina/sites/default/files/ UGA\%202003\%20The\%20Uganda\%20Food\%20and\%20Nutrition\%20Policy. pdf. Accessed 11 June 2018.

7. World Health Organisation. WHO | STEPwise approach to surveillance (STEPS) 2009. Available from: http://www.who.int/chp/steps/en/. Accessed 22 Sept 2015.

8. Bahendeka S, Wesonga R, Mutungi G, Muwonge J, Neema S, Guwatudde D. Prevalence and correlates of diabetes mellitus in Uganda: a populationbased national survey. Tropical Med Int Health. 2016;21(3):405-16.

9. Guwatudde D, Kirunda BE, Wesonga R, Mutungi G, Kajjura R, Kasule H, et al. Physical activity levels among adults in Uganda: findings from a countrywide cross-sectional survey. J Phys Act Health. 2016;13(9):938-45

10. Guwatudde D, Mutungi G, Wesonga R, Kajjura R, Kasule H, Muwonge J, et al. The epidemiology of hypertension in Uganda: findings from the National non-Communicable Diseases Risk Factor Survey. PLoS One. 2015;10(9): e0138991

11. Krauss RM, Eckel RH, Howard B, Appel $\amalg$, Daniels SR, Deckelbaum RJ, et al. AHA dietary guidelines: revision 2000: a statement for healthcare 
professionals from the nutrition Committee of the American Heart Association. Circulation. 2000;102(18):2284-99.

12. World Health Organization. Food based dietary guidelines in the WHO European Region WHO Regional Office for Europe, Scherfigsvej 8, DK-2100 Copenhagen $\varnothing$, Denmark Nutrition and Food Security Programme WHO Regional Office for Europe Scherfigsvej 8, 2100 Copenhagen Denmark, 2003. Available from http://www.euro.who.int/_data/assets/pdf_file/0017/ 150083/E79832.pdf. Accessed 17 May 2018.

13. Zou G. A modified poisson regression approach to prospective studies with binary data. Am J Epidemiol. 2004;159(7):702-6.

14. Yelland LN, Salter AB, Ryan P. Performance of the modified Poisson regression approach for estimating relative risks from clustered prospective data. Am J Epidemiol. 2011;174(4):984-92.

15. Barros AJ, Hirakata VN. Alternatives for logistic regression in cross-sectional studies: an empirical comparison of models that directly estimate the prevalence ratio. BMC Med Res Methodol. 2003;3(1):21.

16. Allen MP. The Problem of Multicollinearity. In: Understanding Regression Analysis. Boston MA: Springer; 1997. p. 176-80. https://doi.org/10.1007/9780-585-25657-3 37

17. Longo M. Democratic Republic of Congo (Ville de Kinshasa) STEPS Survey 2005 Factsheet. 2005. Available from http://www.who.int/ncds/surveillance/ steps/2005_DRC_FactSheet_EN.pdf. Accessed 11 June 2018.

18. Mayige M. Tanzania STEPS Survey 2012 Fact Sheet. 2012. Available from http://www.who.int/chp/steps/UR_Tanzania_FactSheet_2012.pdf?ua=1. Accessed 11 June 2018.

19. Ministry of Health (Zambia) and World Health Organization Country Office (Zambia). Prevalence rates of the common non communicable disease risk factors in Lusaka district, Zambia 2008. 2008. Accessible from http://www.who. int/chp/steps/2008_STEPS_Report_Zambia.pdf. Accessed 11 June 2018.

20. Damasceno AA. Mozambique STEPS Survey 2005 Factsheet. 2005. Available from http://www.who.int/ncds/surveillance/steps/2005_Mozambique_ FactSheet_EN.pdf. Accessed 11 June 2018.

21. Peltzer K, Pengpid S. Fruits and vegetables consumption and associated factors among in-school adolescents in seven African countries. Int J Pub Health. 2010;55(6):669-78.

22. Musinguzi E, Kikafunda JK, Kiremire B. Utilization of indigenous food plants in Uganda: a case study of South-Western Uganda. Afr J Food Agr Nutr Dev. 2006;6(2).

23. Puska P. Health in all policies. Eur J Pub Health. 2006;17(4):328.

24. Bcheraoui EC, Basulaiman M, AlMazroa MA, Tuffaha M, Daoud F, Wilson S, et al. Fruit and vegetable consumption among adults in Saudi Arabia, 2013. Nutr Diet Suppl. 2015;2015(1):41-9.

25. Kim SA, Grimm KA, Harris DM, Scanlon KS, Demissie Z. Fruit and vegetable consumption among high school students--United States. 2010 MMWR. 2011;60(46):1583.

26. Msambichaka B, Eze IC, Abdul R, Abdulla S, Klatser P, Tanner M, et al. Insufficient fruit and vegetable intake in a low-and middle-income setting: a population-based survey in semi-urban Tanzania. Nutrients. 2018;10(2):222.

27. Gibson E, Wardle J, Watts CJ. Fruit and vegetable consumption, nutritional knowledge and beliefs in mothers and children. Appetite. 1998;31(2):205-28.

28. Thompson B, Demark-Wahnefried W, Taylor G, McClelland JW, Stables G, Havas $\mathrm{S}$, et al. Baseline fruit and vegetable intake among adults in seven 5 a day study centers located in diverse geographic areas. J Am Diet Assoc. 1999:99(10):1241-8.

29. Vinther JL, Conklin Al, Wareham NJ, Monsivais P. Marital transitions and associated changes in fruit and vegetable intake: findings from the population-based prospective EPIC-Norfolk cohort, UK. Soc Sci Med. 2016; 157:120-6.

30. Lee $\mathrm{S}$, Cho E, Grodstein F, Kawachi I, Hu FB, Colditz GA. Effects of marital transitions on changes in dietary and other health behaviours in US women. Int J Epidemiol. 2004;34(1):69-78.

31. Umberson D. Gender, marital status and the social control of health behavior. Soc Sci Med. 1992:34(8):907-17.

32. Harvey P, Rambeloson Z, The DO. Uganda food consumption survey: determining the dietary patterns of Ugandan women and children. A2Z The USAID micronutrient and child blindness project. Washington DC: AED; 2008. p. 2010.

33. Kabahenda M, Mullis RM, Erhardt JG, Northrop-Clewes C, Nickols SY. Nutrition education to improve dietary intake and micronutrient nutriture among children in less-resourced areas: a randomised controlled intervention in Kabarole district, western Uganda. South Afr J Clin Nutr. 2011;24(2):83-8.

34. Amone $\mathrm{C}$. We are strong because of our millet bread: staple foods and the growth of ethnic identities in Uganda. TRAMES - J Humanit Soc Sci. 2014; 18(2):159.

35. Uganda Bureau of Statistics and ICF Inc. The Uganda Demographic and Health Survey. Kampala Uganda: Uganda Bureau of Statistics, Kampala, Uganda and Calverton. Maryland: ICF International Inc 2017; 2016. Available from https://www.ubos.org/onlinefiles/uploads/ubos/pdf\%20documents/ Uganda_DHS_2016_KIR.pdf.

36. Uganda Burueau of Statistics and ICF Inc. The Uganda Demographic and Health Survey 2011. Kampala Uganda: Uganda Bureau of Statistics, Kampala, Uganda and Calverton, Maryland: ICF International Inc 2012. Available from https://www.usaid.gov/sites/default/files/documents/1860/Uganda_ Demographic and Health Survey 2011.pdf Access date 28 May 2018.

37. Turyashemererwa F, Kikafunda J, Agaba E. Prevalence of early childhood malnutrition and influencing factors in peri urban areas of Kabarole district, western Uganda. Afr J Food Agric Nutr Dev. 2009;9(4).

38. Kikafunda J, Agaba E, Bambona A. Malnutrition amidst plenty: an assessment of factors responsible for persistent high levels of childhood stunting in food secure Western Uganda. Afr J Food Agric Nutr Dev. 2014; 14(5):2088-113.

39. Uganda Bureau of Statistics. Uganda National Household Survey 2016/2017. Kampala Uganda: Uganda Bureau of Statistics, Kampala, Uganda. 2017. Available from http://www.ubos.org/onlinefiles/uploads/ubos/ pdf\%20documents/UNHS_VI_2017_Version_I_\%2027th_September_2017. pdf. Accessed 28 May 2018.

40. Byers T. Food frequency dietary assessment: how bad is good enough? Am J Epidemiol. 2001;154(12):1087-8

41. Bingham SA, Gill C, Welch A, Day K, Cassidy A, Khaw K, et al. Comparison of dietary assessment methods in nutritional epidemiology: weighed records v. $24 \mathrm{~h}$ recalls, food-frequency questionnaires and estimated-diet records. Brit J Nutr. 1994:72(4):619-43.

\section{Ready to submit your research? Choose BMC and benefit from:}

- fast, convenient online submission

- thorough peer review by experienced researchers in your field

- rapid publication on acceptance

- support for research data, including large and complex data types

- gold Open Access which fosters wider collaboration and increased citations

- maximum visibility for your research: over $100 \mathrm{M}$ website views per year

At $\mathrm{BMC}$, research is always in progress.

Learn more biomedcentral.com/submissions 